\title{
Atypical Presentation of Frontoethmoidal Encephaloceles in a Child - A Case Report
}

\author{
Aditi Jhamb', Divya Ramamoorthy², Syed Athhar Saqqaf ${ }^{3}$, Amar Taksande $^{4}$ \\ 1, 2,3,4 Department of Paediatrics, Jawaharlal Nehru Medical College, Sawangi Meghe, Wardha, Maharashtra, India.
}

\section{INTRODUCTION}

Encephalocele is a form of neural tube defect affecting many children, more common in the occipital regions. The frontoethmoidal encephaloceles (FEE) are rare and the aetiology is unclear since it varies genetically and is linked to multiple reasons. The child with FEE mainly presents with swelling over the bridge of the nose or inner canthus of an eye since birth, with varying degrees of hypertelorism. Here we report a child who has facial asymmetry with FEE. Encephalocele is a defect in the calvarium that causes the cranial contents to protrude outside the natural limits of the skull. It can have meninges (meningocele), brain matter and meninges (meningoencephalocele), or communication with the ventricles.

Suwanwela and Suwanwela defined encephaloceles based on the location and form of skull defect as occipital encephaloceles, cranial vault encephaloceles, frontoethmoidal encephaloceles, and basal encephaloceles. The internal skull defect in frontoethmoidal encephalocele (FEE) is in the midline, but the external skull defect may vary in the facial bony structure. ${ }^{1-3}$ It is also classified into three subtypes: nasofrontal (NF), naso-ethmoidal (NE), and naso-orbital (NO). These swellings are classified as sessile or pedunculated, and their palpability ranges from robust and rigid to soft and cystic. We present a case of an infant with frontoethmoidal encephaloceles as well as a facial deformity.

\section{PRESENTATION OF CASE}

A two-year-old male boy born from a non-consanguineous marriage was taken to the clinic with symptoms of facial deformity from birth. There was no history of difficulty in eating, swallowing, or regurgitation of food through the nose \& mouth. There was no history of nasal blockage, nasal bleeding, and trauma. He did not have any complaints of decreased hearing. He was born full-term, appropriate for gestational age via normal vaginal delivery.

No history of maternal illness during pregnancy. His mental and motor milestones were normal. On physical examination, the patient was conscious and co-operative. On general examination, the child was afebrile, pale, anicteric, with no signs of cyanosis, clubbing, lymphadenopathy, and pedal oedema. At the time of examination, the patient's body temperature was $37.2^{\circ} \mathrm{C}$ with a pulse rate of 104 beats/min, with good volume, which was regular and synchronous. Respiratory rate was 28 cycles/min, oxygen saturation was $99 \%$ and blood pressure was 100/60 $\mathrm{mmHg}$.

\author{
Corresponding Author: \\ Dr. Amar Taksande, \\ Department of Paediatrics, \\ Jawaharlal Nehru Medical College, \\ Sawangi Meghe, Wardha - 442004, \\ Maharashtra India. \\ E-mail:amar.taksande@gmail.com
}

DOI: $10.14260 / j e m d s / 2021 / 549$

How to Cite This Article:

Jhamb A, Ramamoorthy D, Saqqaf SA, et al. Atypical presentation of frontoethmoidal encephaloceles in a child - a case report. J Evolution Med Dent Sci 2021;10(32):26892691, DOI: 10.14260/jemds/2021/549

Submission 21-04-2021,

Peer Review 05-07-2021,

Acceptance 11-07-2021,

Published 09-08-2021.

Copyright (C) 2021 Aditi Jhamb et al. This is an open access article distributed under Creative Commons Attribution License [Attribution 4.0 International (CC BY 4.0)] 
He had a facial deformity with a short neck. The hairline extends from the left side of the forehead to the glabella, the right ala of the nose arises on the root of the nose and the rightsided medial canthus is deviated downwards (Fig 2). The child could not close the right eye. There was no spine and chest deformity. Neurological examination revealed a normal motor and sensory system. There were no craniospinal, ribs, or limb anomalies. Other systemic examinations did not reveal any abnormality. Complete blood count showed haemoglobin of 14.6 gm \%, total leukocyte count (TLC) - 5800, platelet 2.7 lakhs. His investigations revealed a haemogram within normal range, normal blood urea nitrogen, and serum creatinine. Xray of skull, spine, and chest were normal.

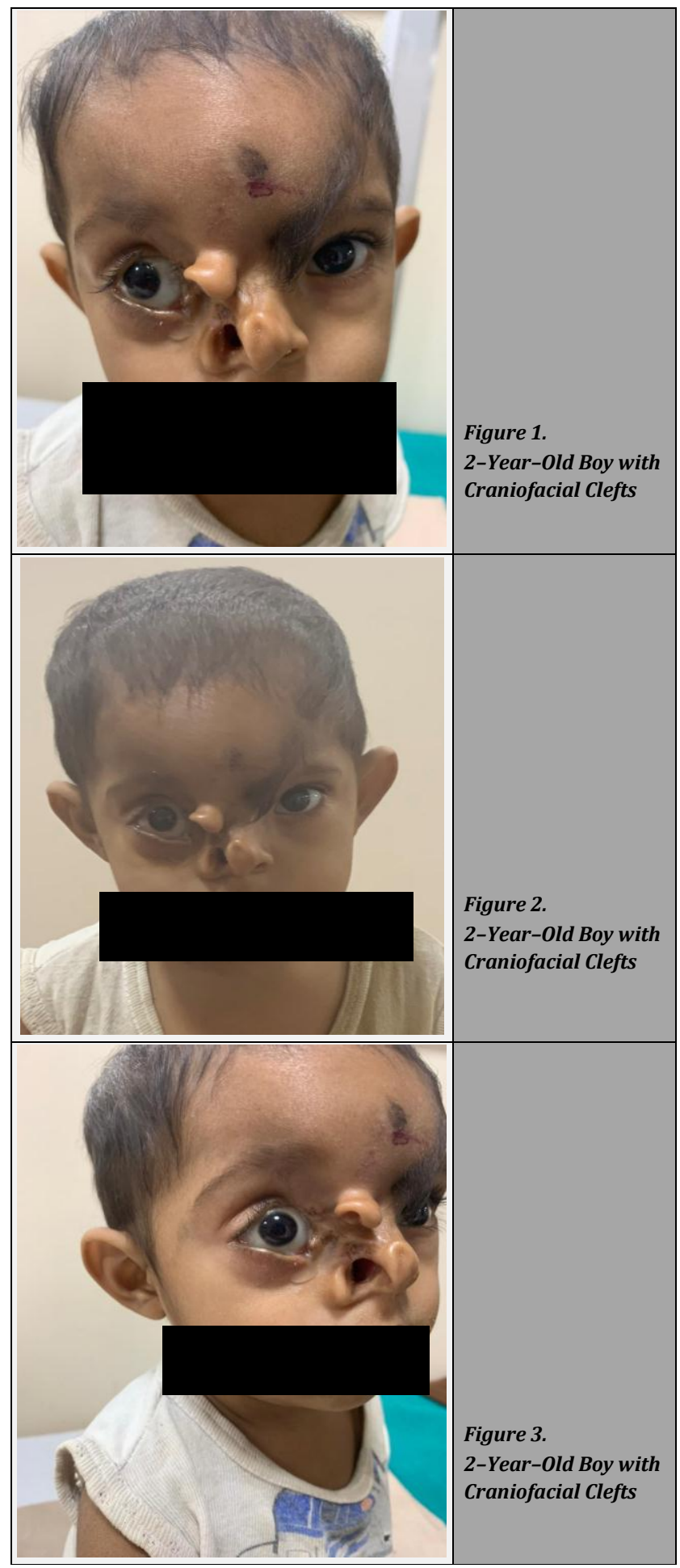

2D echocardiography was suggestive of a $70 \%$ ejection fraction with no cardiac defect. Thyroid function was within normal limits. Computed tomography (CT) scan revealed a focal defect in the left base - frontal bone with mild herniation of adjacent brain parenchyma extending to front-ethmoidal recess on the right side till the level of soft tissue at the root of the nose which was suggestive of frontoethmoidal encephaloceles. The plan of treatment was reconstructive surgery. So, the child was referred to the department of oral maxillofacial surgery.

\section{DISCUSSION}

Encephalocele is an unusual case of neural tube defect that affects the brain. It can be congenital or acquired secondary to tumour, hydrocephalus, or other cause. Some suggest that ethnic, genetic, environmental factors and paternal age could be the aetiology of encephalocele. ${ }^{2-4}$ The incidence of frontoethmoidal encephaloceles is between 0.8 to 4 per 10,000 births and there's no reported sex predominance. They are very common in South-East Asian countries. Presentation depends on the site and size of the defect and protrusion if large then clearly the facial deformity will be present with a mass of variable appearance (sessile or pedunculated; normal complexion or pigmentation, soft or firm, may have hypertrichosis) 3. According to the Suwanwela and Suwanwela classification, the patient here presented as a frontoethmoidal encephalocele, subtype naso-ethmoidal, associated with craniofacial clefts. FEE manifests as a clinically identifiable mass along with the nose. It is present intracranially in the foramen caecum, a thin ostium situated at the bottom of a small depression anterior to the crista Galli and created by the closure of both frontal and ethmoid bones. ${ }^{4-6}$

This child came with complaints of facial deformity in the form of a facial cleft with the right ala of the nose not being fused with the rest of the nose and remained unfused near the inner canthi of the right eye. The patient, therefore, had exposed nasal mucosa of the right side with an open nasolacrimal duct. The patient also had a tuft of hair present medially to the left eyebrow as an extension of the frontal hairline. The patient also could not close the right eye. A frontoethmoidal encephalocele was discovered using a CT scan of the brain. Recurrent meningoencephalitis can be exacerbated by overt contact of the central nervous system with the surrounding environment, which allows pathogenic microorganisms to enter. Streptococcus pneumonia is the most prevalent bacteria associated with meningitis in such patients, followed by Staphylococcus aureus and Neisseria meningitides. Differential diagnoses of this might be traumatic encephalocele, ethmoid-frontal sinus mucocele, neurinoma, haemangioma and glioma. Multilayer reconstructive surgery is a method that gives excellent results with a high success rate and is advocated as a treatment for such conditions. ${ }^{5-8}$

\section{CONCLUSIONS}

In conclusion, early detection and early surgical intervention are very important, so that the deformity doesn't progress and to prevent infection if an encephalocele has ruptured. Our case 
has some rarely reported features such as facial asymmetry, craniofacial clefts with FEE prompting us to report this case.

Financial or other competing interests: None.

Disclosure forms provided by the authors are available with the full text of this article at jemds.com.

\section{REFERENCES}

[1] Diebler C, Dulac 0. Cephaloceles: clinical and neuroradiological appearance. Associated cerebral malformations. Neuroradiology 1983;25(4):199-216.

[2] Suwanwela C, Suwanwela N. A morphological classification of sincipital encephalomeningoceles. J Neurosurg 1972;36(2):201-11.

[3] David DJ. Cephaloceles: classification, pathology and management--a review. J Craniofac Surg 1994;4(4):192202.
[4] Thu A, Kyu H. Epidemiology of frontoethmoidal encephalomeningocoele in Burma. J Epidemiol Community Health 1984;38(2):89-98.

[5] Bhattacharjee A, Chakraborty A, Purkaystha P. Frontoethmoidal encephalomeningocoele with colpocephaly: case report and clinical review. J Laryngol Otol 2008;122(03):321-3.

[6] Hoving EW, Vermeij-Keers C. Frontoethmoidal encephaloceles, a study of their pathogenesis. Pediatr Neurosurg 1997;27(5):246-56.

[7] Dhirawani RB, Gupta R, Pathak S, et al. Frontoethmoidal encephalocele: case report and review on management. Ann Maxillofac Surg 2014;4(2):195-7.

[8] Holmes AD, Meara JG, Kolker AR, et al. Frontoethmoidal encephaloceles: reconstruction and refinements. J Craniofac Surg 2001;12(1):6-18. 